\title{
Memória, cognição e afetividade: um estudo acerca de processos de retomada em aulas de Física do Ensino Médio
}

\section{Memory, cognition and affectivity: a study about processes of recalling during High School Physics classes}

\author{
Marta Maximo Pereira ${ }^{1}$ - Maria Lucia Vital dos Santos Abib ${ }^{2}$
}

\begin{abstract}
Resumo: Várias pesquisas apontam que estudantes costumam ter dificuldades para retomar conhecimentos com os quais tiveram contato previamente. Neste trabalho, apresentamos elementos que nos permitiram compreender as retomadas de conhecimentos e de situações vivenciadas pelos estudantes em aulas de Física de momentos anteriores de sua escolarização. A perspectiva sócio-histórico-cultural foi a fundamentação teórica utilizada, em especial, os conceitos de cognição, afetividade e memória mediada. Os registros foram coletados em aulas de Física do Ensino Médio. Como resultado, construímos duas categorias: memória científico-afetiva e memória afetivo-vivencial. A primeira se refere ao que foi retomado pelos alunos e que guarda estreita relação com o conhecimento científico escolar e/ou é influenciado por ele. Já a memória afetivo-vivencial diz respeito ao que foi retomado e que não tem relação explícita com o conhecimento científico escolar. Consideramos que nossas categorias podem auxiliar na compreensão dos processos de aprendizagem de Física ao longo do tempo.
\end{abstract}

Palavras-chave: Memória. Cognição. Afetividade. Aprendizagem. Ensino de física. Ensino médio.

\begin{abstract}
Several researches point out that students often have difficulty recalling knowledge they have already had contact with in school. In this paper, we present elements that have allowed us to comprehend recall of knowledge and situations experienced by students from previous Physics classes. Sociocultural perspective was the theoretical framework used, especially the concepts of cognition, affectivity and mediated memory. The records were collected during High School Physics classes, in Brazil. As a result, we have elaborated two categories: scientific-affective memory and affective-living memory. The former corresponds to what has been recalled and has a close relationship to scientific knowledge and/or is influenced by it. The latter refers to what has been recalled and has no explicit relationship to scientific knowledge. We consider that our categories may help the understanding of processes of learning Physics over time.
\end{abstract}

Keywords: Memory. Cognition. Affectivity. Learning. Physics teaching. High school.

\footnotetext{
${ }^{1}$ Centro Federal de Educação Tecnológica Celso Suckow da Fonseca (CEFET/RJ), Nova Iguaçu, RJ, Brasil. E-mail: <martamaximo@yahoo.com>.

${ }^{2}$ Universidade de São Paulo (USP), Faculdade de Educação, Departamento de Metodologia do Ensino e Educação Comparada, São Paulo, SP, Brasil.
} 


\section{Introdução}

Os processos de ensino e aprendizagem de ciências em geral e de Física, em particular, sempre despertaram (e seguem despertando) a atenção e o interesse de pesquisadores nas áreas de educação e ensino de ciências (CARVALHO, 2004; VASCONCELOS; PRAIA; ALMEIDA, 2003). A variedade e a complexidade das formas por intermédio das quais as pessoas aprendem têm sido evidenciadas em muitos estudos, o que aponta para um interessante e frutífero campo de investigação (MARTÍNEZ; TACCA, 2010).

Consideramos que os indivíduos aprendem por intermédio de diferentes estratégias, influenciados por múltiplas variáveis e ao longo do tempo. Para Sastre e Moreno (2003, p. 143), "[...] é necessário partir da ideia de que toda a aprendizagem é um processo dinâmico e, como tal, requer uma construção, e essa, por sua vez, requer algum tempo".

Entendemos que aprender é um processo contínuo de reconstruções internas do sujeito com base em construções coletivas em seu ambiente social e cultural. Sobre o conceito de aprendizagem, concordamos com Almeida e Antunes (2005, p. 10), quando afirmam que

[...] pode-se definir aprendizagem como sendo a apropriação pelo indivíduo dos conhecimentos historicamente acumulados pela humanidade, compreendendo estes desde as produções acadêmicas/formais até os hábitos cotidianos de uma sociedade; enfim, é a apropriação das ações práticas e teóricas elaboradas social e historicamente. Nessa conceituação está sintetizada tanto a aquisição de conteúdos quanto a consolidação dos mesmos na memória e a conexão dinâmica dessas informações com os demais conteúdos anteriormente apropriados pelo indivíduo em sua atividade.

Em especial, consideramos que aquilo que se ensina nas aulas de Física precisa ser aprendido de modo duradouro e com possibilidades de que seja utilizado e ressignificado em novas situações, pois concordamos com Finkel (2008, p. 37, tradução nossa) que "[...] a educação deveria buscar aprendizagens relevantes, de longa duração, que alterassem para sempre nossa apreciação do mundo, aprofundando-a, ampliando-a, generalizando-a, agudizando-a". No entanto, como podemos ter indícios de que tal finalidade da educação está sendo atingida?

Barros (2002, p. 14) sugere que haja mais "[...] pesquisas longitudinais brasileiras desenvolvidas de forma abrangente sobre temas de interesse atual para o ensino de física", pois não são muitas as investigações existentes que se dedicam a estudar a aprendizagem considerando-se um tempo mais ou menos longo após os momentos iniciais da escolarização em Física (CARVALHO; GIL-PÉREZ, 2001; MERCER, 2008).

Por exemplo, no que se refere à retomada, em longo prazo, de conhecimentos e situações vivenciados em aulas de Física, Carvalho e Gil-Pérez (2001) relataram uma pesquisa feita com profissionais liberais que não tiveram contato com essa disciplina em seus cursos de graduação. Ao serem perguntados sobre o que se lembravam da Física que lhes foi ensinada no nível médio, mais de 70\% deles disseram que não recordavam nada do que estudaram ou que se lembravam somente dos principais tópicos estudados (mecânica, óptica, eletricidade, etc.). Os demais retomaram de maneira muito geral o que foi apresentado nas aulas e, durante a entrevista, não foram capazes, de acordo com a pesquisa, de explicar nenhum conceito-chave da disciplina. 
Interessa-nos, neste trabalho, aprofundar o entendimento acerca da aprendizagem de Física em contexto escolar, considerando suas dimensões temporal e processual. Para tanto, utilizamos a ideia de retomada, entendida como reelaboração de um conhecimento ou de uma situação, experienciada previamente, em um novo contexto.

Assim, o objetivo do presente texto é apresentar elementos que colaborem para que se possa compreender as retomadas de conhecimentos e situações vivenciadas pelos estudantes em aulas de Física de momentos anteriores de seu processo de escolarização. As categorias de análise foram elaboradas pela interação entre elementos teóricos e dados empíricos. Estes últimos foram construídos por intermédio de registros coletados junto a estudantes de Ensino Médio em aulas de Física, durante uma pesquisa de Doutorado em Ensino de Ciências. Consideramos a perspectiva sócio-histórico-cultural como fundamentação teórica deste estudo, em especial, os conceitos de cognição, afetividade, memória mediada e suas interrelações.

\section{Fundamentação Teórica}

Quando pensamos no que influencia ou está relacionado à aprendizagem ao longo do tempo, parece-nos essencial considerar a presença da memória, pois temos por hipótese que conseguimos retomar por ela, de alguma forma, aquilo que aprendemos. No entanto, acreditamos também que nem tudo que retomamos pela memória foi de fato aprendido. Vale lembrar que utilizamos o conceito de memória na perspectiva da psicologia (amparados pelas ideias vigotskianas), e não na perspectiva da neurociência.

A memória, enquanto função psicológica elementar, é denominada memória natural por Vigotski (2007), sendo caracterizada pela impressão não mediada de materiais e pela retenção de experiências reais, sendo consequência direta dos estímulos externos sobre o ser humano. Tal tipo de memória, de acordo com esse autor, é predominante em povos iletrados. Todavia, mesmo neles, "[...] coexistem com ela outros tipos de memória pertencentes a linhas de desenvolvimento totalmente diferentes" (VIGOTSKI, 2007, p. 32).

No contexto de uma cultura letrada, a partir da infância e ao longo da escolarização, os indivíduos vão desenvolvendo, por intermédio de suas relações em sociedade, funções psicológicas superiores, como, por exemplo, a memória lógica, que é de origem sociocultural e mediada por signos. Para Bakhurst (2002, p. 237-238),

[...] a função mental superior da memória nos permite buscar à vontade uma imagem ou um relato do passado. Nesta memória voluntária ou "lógica", não é que a mente seja simplesmente provocada por algum choque do presente a "ir e pegar" uma imagem; ao contrário, o passado é deliberadamente relembrado por uma razão determinada. Vygotsky argumenta que a memória lógica se torna possível graças ao poder mediador dos signos. Usando signos como auxiliares da memória, os seres humanos são capazes de controlar deliberadamente as condições de suas recordações futuras.

Assim, consideramos que, ao lembrarmos alguma ideia ou situação, ela se transforma em algo diferente, devido à mediação realizada. Mesmo que se queira memorizar alguma coisa, a 
“cópia” na memória nunca é idêntica ao que se quer memorizar, tampouco uma réplica perfeita, pois tal processo não é direto, mas sim mediado.

No contexto de salas de aula do Ensino Médio, a retomada de alguma ideia ou situação, com a qual o aluno já teve contato há algum tempo, ocorre por intermédio de uma mediação, com um objeto externo relembrando-o daquilo que ele quer recordar. A partir da adolescência, a memória do jovem “[...] está tão 'carregada de lógica' que o processo de lembrança está reduzido a estabelecer e encontrar relações lógicas; o reconhecer passa a considerar em descobrir aquele elemento que a tarefa exige que seja encontrado" (VIGOTSKI, 2007, p. 49).

Para Vigotski (2007, p. 31), o conceito de memória é “[...] excepcionalmente apropriado para o estudo das mudanças introduzidas pelos signos nas funções psicológicas, uma vez que revela com clareza a origem social dos signos e o seu papel crucial no desenvolvimento individual". A memória lógica é desencadeada no plano interpessoal (via interação social) e transformada em um processo intrapessoal com o uso de signos. Concordamos com Bakhurst (2002, p. 249), quando afirma, tendo a obra de Voloshinov³ (1927 apud BAKHURST, 2002, p. 249) como referência, que

[...] a essência social da memória individual decorre simplesmente da constituição social de todos os estados mentais. Nesta posição, lembrar é sempre fazer uma leitura do passado, uma leitura que requer habilidades linguísticas derivadas das tradições de explicação e narração dentro de uma cultura, e que desemboca numa narrativa que deve seu significado em última instância às práticas interpretativas de uma comunidade de falantes. Isso é verdade até mesmo quando o que é lembrado é a experiência passada do próprio indivíduo.

Assim, compreendemos que a formação da memória se dá por intermédio da interação do sujeito com o mundo, ao longo das relações sociais que ele estabelece, nos mais diferentes âmbitos de sua vida. Tendo em vista a sala de aula, acreditamos que as retomadas dos alunos estão permeadas não só de conceitos, leis, teorias e fórmulas, mas também de procedimentos, atitudes e valores que, com mais ou menos profundidade, em maior ou menor escala, eles tenham construído ao longo das aulas.

Ao compreendermos a aprendizagem escolar como sendo um processo de apropriação das produções humanas historicamente acumuladas em uma cultura, devemos considerar o fato de que cada ser humano possui uma coleção pessoal de fatos, conhecimentos, situações e vivências que pode, quer ou consegue retomar. Mesmo que duas ou mais pessoas tenham muitas vivências em comum, tenham compartilhado muitas experiências e sejam muito parecidas em sua forma de ser, pensar e agir, aquilo que uma delas consegue retomar e o modo como

\footnotetext{
${ }^{3}$ Enquanto os estudos vigotskianos se concentram num gênero específico de rememoração (recordação de listas mediada pelo uso de dispositivos mnemônicos), as conclusões de Voloshinov sobre memória são de natureza mais geral, enfatizando a constituição social de todas as formas de memória individual. Contudo, as considerações de Voloshinov estão de acordo com a perspectiva de Vigotski (BAKHURST, 2002).
} 
acontecem as retomadas são sempre (e necessariamente) distintos do de outra pessoa. Cada ser humano, ainda que em presença de uma mesma situação e sob condições similares, percebe essa situação e leva-a consigo de formas diferentes e originais.

Pensando na sala de aula, diante de uma mesma explicação de um dado conteúdo, mesmo em uma turma que se mantém unida por muito tempo, formada por alunos que possuem uma formação prévia similar e que compartilham pensamentos, motivações e interesses, nenhum desses elementos garante que todos os estudantes aprenderão (ou não) da mesma forma. Em outras palavras, a aprendizagem é influenciada sobremaneira pelas vivências dos estudantes em diferentes aspectos de sua vida e pelas retomadas que fazem das (e nas) situações de aprendizagem. De acordo com Almeida e Antunes (2005, p. 11),

\begin{abstract}
[...] quando um conteúdo é aprendido, o indivíduo memorizou aquelas informações que, em conexão com aquelas por ele já apropriadas, são significadas ou re-significadas; isto é, o indivíduo promove a síntese de seus conhecimentos, alterando assim sua compreensão da realidade. Essa alteração - ou seja, o quanto, o que e até mesmo quando, haja vista que um dado conhecimento pode ter novas significações durante o tempo - é muito variável, pois depende não só dos conteúdos apropriados, mas também de como o indivíduo significou estes conhecimentos (sentido pessoal) e do tipo de apropriação que foi realizado, se baseado em conceitos espontâneos ou científicos, se na cotidianidade ou por meios sistematizados, assim como por quais caminhos esse conhecimento chegou a ele.
\end{abstract}

Sabemos que algumas situações vividas são mais lembradas do que outras e que algumas informações com as quais temos contato são mais facilmente retomadas do que outras. Por que isso acontece? Que elementos influenciam a memória? É possível identificar aspectos que facilitem as retomadas pela memória?

Está claro que, por mais frutíferas que sejam as interações sociais na sala de aula, por mais instigantes que sejam os conteúdos e por mais desafiadoras que sejam as propostas de ensino utilizadas pelo professor, é humanamente impossível que uma pessoa se lembre de tudo que lhe foi ensinado ao longo de seus anos de escolarização. Mas o que ela consegue retomar? O que a levou a lembrar-se disso? Aquilo de que ela se lembra foi de fato aprendido? Como aquilo de que ela se lembra influencia as aprendizagens futuras?

Acreditamos ser necessário considerar o modo como as relações interpessoais influenciam os indivíduos para que se possa compreender como ocorrem as retomadas pela memória, pois "[...] cada sujeito elabora, reage e lida de modo singular com as mesmas determinações e influências sociais" (OLIVEIRA; REGO, 2003, p. 23). De acordo com Izquierdo (2002, p. 12), "[...] todos sabemos como é fácil aprender ou evocar algo quando estamos alertas e de bom ânimo; e como fica difícil aprender qualquer coisa ou até lembrar o nome de uma pessoa ou de uma canção quando estamos cansados, deprimidos e muito estressados."

Desse modo, entendemos que aspectos afetivos influenciam fortemente as retomadas que fazemos pela memória e, consequentemente, aquilo que aprendemos. De acordo com a versão eletrônica do Dicionário Houaiss da língua portuguesa, na rubrica de psicologia, afetividade significa o "conjunto de fenômenos psíquicos que são experimentados e vivenciados na 
forma de emoções e de sentimentos". Esse conceito, em nossa pesquisa, não é sinônimo de amor ou carinho, pois concordamos com Mahoney e Almeida (2005, p. 1) quando afirmam que "[...] afetividade refere-se à capacidade, à disposição do ser humano de ser afetado pelo mundo externo/interno sempre acompanhado de sensações ligadas a tonalidades agradáveis ou desagradáveis".

Compreendemos que os fenômenos afetivos referem-se a experiências subjetivas, que revelam a forma como cada sujeito "[...] é afetado pelos acontecimentos da vida ou, melhor, pelo sentido que tais acontecimentos têm para ele" (PINO, 2000, p. 128). Em outras palavras, consideramos que a afetividade é a capacidade que os indivíduos têm de serem positiva ou negativamente afetados, com maior ou menor intensidade, por uma dada situação, de forma que cada um deles estabelece um tipo de relação afetiva com essa situação e lhe atribui um sentido particular. Por isso, estamos de acordo com Cacheffo e Garms (2011, p. 9), quando afirmam que "[...] dentre as implicações da afetividade no desenvolvimento humano, os estudos apontam [...] a relação indissociável com a cognição e a capacidade de afetar de maneira positiva ou negativa, o processo de ensino e aprendizagem".

Sabemos que a psicologia tem por tradição separar as dimensões cognitiva e afetiva do ser humano, com o objetivo de estudar cada uma delas separadamente, de forma mais aprofundada. Todavia, para Vigotski (2009, p. 16), “[...] em toda ideia existe, em forma elaborada, uma relação afetiva do homem com a realidade representada nessa ideia”.

Oliveira e Rego (2003, p. 32) afirmam também que “[...] de acordo com o paradigma elaborado por Vygotsky ${ }^{4}$, é necessário investigar a história singular dos sujeitos para que se possa de fato construir uma compreensão aprofundada de seus processos de desenvolvimento." Assim, Vigostki (2009, p. 16) critica a separação entre as dimensões cognitiva e afetiva do funcionamento psicológico, adotando uma abordagem unificadora entre elas:

[...] como se sabe, a separação entre a parte intelectual da nossa consciência e sua parte afetiva e volitiva é um dos defeitos radicais de toda a psicologia tradicional. [...] Quem separou desde o início o pensamento do afeto fechou definitivamente para si mesmo o caminho para a explicação das causas do próprio pensamento, porque a análise determinista do pensamento pressupõe necessariamente a revelação dos motivos, necessidades, interesses, motivações e tendências motrizes do pensamento, que lhe orientam o movimento nesse ou naquele aspecto. (VIGOSTKI, 2009, p. 16, grifo nosso).

Tendo como foco a aprendizagem dos estudantes em contexto escolar, consideramos que eles são afetados de diferentes modos por suas relações com os demais colegas, com o professor, com as atividades propostas e com o conhecimento científico escolar. Ademais, não podemos ignorar o fato de que cada aluno traz consigo um conjunto de experiências prévias,

\footnotetext{
${ }^{4}$ Optamos por manter a escrita do nome do autor conforme consta no trabalho original citado.
} 
Memória, cognição e afetividade: ...

construídas anteriormente na escola e em outros espaços, as quais podem igualmente afetar positiva ou negativamente o seu aprendizado. Segundo Sastre e Moreno (2003, p. 143), para a compreensão do processo de aprendizagem

[...] devem ser tecidas as relações entre aspectos cognitivos e afetivos, entre fenômenos científicos e cotidianos, entre os aspectos considerados pertencentes à vida pública e os considerados exclusivos da vida privada, para reunir o que já havia sido arbitrariamente separado e que provoca cisões, também arbitrárias, no psiquismo dos estudantes.

\section{Metodologia}

Realizamos uma pesquisa interpretativa, de abordagem qualitativa (MOREIRA; CALEFFE, 2008). Os dados foram construídos por intermédio de registros obtidos em diferentes instrumentos de coleta, durante uma pesquisa mais ampla, de Doutorado em Ensino de Ciências (PEREIRA, 2014).

Em tal investigação, realizamos observação participante em uma turma de 22 alunos de Ensino Médio, de uma instituição federal de ensino, durante aulas de Física, por seis meses em 2012 e por duas semanas em 2013. O conteúdo trabalhado com a turma em 2012, na disciplina Física II, era relativo à Física Térmica. Em 2013, os estudantes participaram de outras atividades, diferentes das iniciais, mas que versavam sobre o que foi trabalhado com eles pelo professor em 2012. Nos dois momentos, as aulas e atividades de retomada foram ministradas pelo mesmo docente. A pesquisadora acompanhava as atividades e interagia com os estudantes, mas não ministrava as aulas.

No Quadro 1, apresentamos as atividades que serão mencionadas na análise de dados, as quais foram aplicadas no segundo momento da pesquisa, em 2013.

As análises aqui apresentadas foram feitas tanto no âmbito de toda a turma investigada (Alunos de 1 a 22) como considerando um pequeno grupo de estudantes, formado pela Aluna 1, pelos Alunos 3 e 4, pela Aluna 16 e pelo Aluno 19. Vale lembrar que os dados presentes em nossos resultados são apenas um pequeno recorte daqueles construídos no âmbito de nossa tese de doutorado e que os critérios de seleção dos mesmos foram o fato de serem, em nosso entendimento, mais representativos do que queríamos explicitar e o espaço disponível para este texto.

As categorias elaboradas constituem-se em sínteses das análises de dados realizadas com base em nossa fundamentação teórica. 
Quadro 1. Atividades de retomada, aplicadas em 2013 e utilizadas na análise de dados

\begin{tabular}{|c|c|c|}
\hline Nome da atividade & Descrição da atividade & Registros coletados \\
\hline $\begin{array}{l}\text { Atividade 1: } \\
\text { Sensibilização dos } \\
\text { alunos para as situações } \\
\text { de aprendizagem da } \\
\text { disciplina Física II e } \\
\text { para os assuntos nela } \\
\text { trabalhados }\end{array}$ & $\begin{array}{l}\text { O professor escreveu no quadro a palavra } \\
\text { calor e pediu que os alunos dissessem o que } \\
\text { recordavam por conta dessa palavra. O } \\
\text { professor ia escrevendo no quadro o que os } \\
\text { alunos falavam. Repetiu esse procedimento } \\
\text { para a palavra temperatura. O professor pediu } \\
\text { que os alunos discutissem em pequeno grupo } \\
\text { e elaborassem sínteses dessas discussões. }\end{array}$ & $\begin{array}{l}\text { Falas dos estudantes entre } \\
\text { si e com o professor e a } \\
\text { pesquisadora em pequeno } \\
\text { grupo; texto escrito por } \\
\text { cada grupo como síntese } \\
\text { do que se lembravam das } \\
\text { aulas de Física II }\end{array}$ \\
\hline $\begin{array}{l}\text { Atividade 2: Reflexão } \\
\text { sobre a aprendizagem } \\
\text { durante a disciplina } \\
\text { Física II }\end{array}$ & $\begin{array}{l}\text { O professor distribuiu um questionário aos } \\
\text { alunos e pediu que eles o respondessem, } \\
\text { considerando as aulas da disciplina Física II. }\end{array}$ & $\begin{array}{l}\text { Respostas escritas } \\
\text { a questionário com } \\
\text { perguntas abertas }\end{array}$ \\
\hline $\begin{array}{l}\text { Atividade 3: Contraste } \\
\text { entre os conceitos } \\
\text { espontâneos e } \\
\text { científicos de calor e } \\
\text { temperatura }\end{array}$ & $\begin{array}{l}\text { O professor propôs aos grupos de alunos } \\
\text { a resolução da questão } 50 \text { da prova azul } \\
\text { do primeiro dia de prova do ENEM de } \\
2010 \text {. Informou que os grupos deveriam } \\
\text { indicar também porque as outras opções de } \\
\text { resposta disponíveis eram incorretas. Após } \\
\text { a resolução, cada grupo iria apresentar a sua } \\
\text { solução para toda a turma, em forma de } \\
\text { discussão coletiva. }\end{array}$ & $\begin{array}{l}\text { Falas dos estudantes em } \\
\text { pequeno grupo }\end{array}$ \\
\hline
\end{tabular}

Fonte: elaborado pelas autoras.

\section{Resultados e discussão}

Para investigar a forma como os estudantes realizaram suas retomadas relativas ao que estudaram e vivenciaram previamente nas aulas de Física, estabelecemos duas categorias de memória enquanto função mental superior (VIGOTSKI, 2007), por nós denominadas memória cientifico-afetiva e memória afetivo-vivencial.

Incluímos na categoria denominada memória científico-afetiva aquilo que o sujeito retoma dos momentos do ensino de Física e que guarda estreita relação com o conhecimento científico escolar e/ou é influenciado por ele. Grande parte desses dados refere-se, de forma geral, a conhecimentos estudados no ano anterior. Muito frequentemente os alunos utilizaram a linguagem científica para expressar seus conhecimentos, valendo-se de vocabulário específico da Física, o que reforça a presença da Física escolar nessa memória.

No Quadro 2, apresentamos dados que foram categorizados como pertencentes ao âmbito da memória científico-afetiva. Eles são fragmentos de textos escritos por grupos de alunos 
como síntese da Atividade 1: Sensibilização dos alunos para as situações de aprendizagem da disciplina Física II e para os assuntos nela trabalbados, na qual os estudantes eram levados a retomar conhecimentos e situações com os quais tinham tido contato no ano anterior. Uma descrição mais detalhada da Atividade 1 pode ser vista em Pereira (2014).

Quadro 2. Conhecimentos compatíveis com o conhecimento científico-escolar identificados nos textos escritos por quatro dos cinco grupos investigados

\begin{tabular}{|c|c|}
\hline Grupos & Dados (em itálico) \\
\hline Grupo 1 & $\begin{array}{l}\text { Rendimento de uma máquina térmica não pode chegar a 100\% } \\
\text { Transferência de Energia (Calor) }\end{array}$ \\
\hline Grupo 3 & $\begin{array}{l}\text { Quanto maior a profundidade maior a pressão atm. } \\
\text { Energia - capacidade de realizar trabalho } \\
\text { A energia não utilizada no trabalho se transforma calor. } \\
\text { O ponto de ebulição da água em [local onde fica a escola] é cerca de } 98^{\circ} \mathrm{C} \text {, por não estarmos a } 1 \text { atm e } \\
\text { água não e pura. }\end{array}$ \\
\hline Grupo 4 & $\begin{array}{l}\text { Me lembro do experimento da água (Não se pode medir temperatura com a mão). } \\
\text { Calor Latente: sem variação de temperatura } \\
\text { Calor Sensivel: com variação de temperatura } \\
\text { Quanto mais profundo, maior a pressão. Questão do sino da 2a Avaliação. } \\
\text { Em uma placa de metal, se fizermos um circulo e retirá-lo, se aquecer a placa e o círculo, ele encaixa } \\
\text { porque ocorre o "fenômeno" da dilatação. } \\
\text { O calor é transferido a partir da variação da vibração das moléculas que colidem uma com as outras... } \\
\text { Sobre o ar condicionado. O ar mais quente é menos denso que o frio. } \\
\text { Um corpo com temperatura T1 (quente) e outra com temperatura T3 (frio). Quando o corpo T1 } \\
\text { "transferir" calor para o T3 eles vão atingir a temperatura intermediária T2 } \\
\text { Isolantes: Isopor, o ar, madeira } \\
\text { O casaco de lã esquenta porque tem "espaço" pro ar, que é um bom isolante térmico. } \\
\text { Sobre dilatação dos pisos da casa. Por isso que os pedreiros colocam uma separação ou fornecem um } \\
\text { espaço entre os pisos porque no calor dilata. A mesma coisa épara as paredes da casa que quando } \\
\text { resfriam provocam estalo. } \\
\text { O fogão tem que ficar afastado da parede (se for de piso) porque a temperatura do fogão pode causar o } \\
\text { estufamento da parede. } \\
\text { Zero absoluto. É quando não tem mais movimento algum das partículas. } \\
\text { Kelvin: } 273 \text { - } 373 \\
\text { Celsius: } 0^{\circ} \text { - } 100^{\circ}\end{array}$ \\
\hline Grupo 5 & $\begin{array}{l}\text { Quanto menor a área maior a pressão. } \\
\text { O casaco de moletom do Mikey da Aluna } 18 \text { retém mais calor do que um casaco jeans. } \\
\text { A lãé um bom isolante térmico pois em seus "buracos" possui ar que retém mais calor } \\
\text { Se aquecer a porca, ela dilata e conseque-se tirar o parafuso } \\
\text { Os corpos liquidos também se dilatam, um exemplo em aula foi a gasolina }\end{array}$ \\
\hline
\end{tabular}

Fonte: elaborado pelas autoras. 
É importante notar que a memória científico-afetiva é permeada por conhecimentos compatíveis com a ciência escolar, os quais podem ser usados de diferentes formas pelos estudantes em suas retomadas posteriores ao momento de aprendizagem inicial. Aspectos afetivos podem aparecer nos dados, como em situações de retomadas de momentos anteriores da escolarização (Grupos 4: Me lembro do experimento da água; Questão do sino da 2a Avaliação) ou em exemplos de apropriação de conhecimento científico escolar em contextos explicitamente familiares aos grupos (O ponto de ebulição da água em [local onde fica a escola] - Grupo 3; O casaco de moletom do Mikey da Aluna 18 retém mais calor do que um casaco jeans-Grupo 5). No entanto, frequentemente os aspectos afetivos da memória científico-afetiva estão implícitos ou podem ser explicitados considerando-se as interações iniciais dos estudantes com o conhecimento científico escolar retomado.

É interessante chamar a atenção para o fato de que nem sempre os dados categorizados como pertencentes à memória científico-afetiva foram expressos de forma direta e explícita pelos estudantes, como os que aparecem no Quadro 2.

Por exemplo, a análise da discussão em pequeno grupo, a qual precedeu a escrita dos registros que deram origem aos dados do Quadro 2, ainda na Atividade 1, também permitiu a construção de dados que foram categorizados como pertencentes à memória científico-afetiva, pelo menos no Grupo 2, o qual teve suas interações analisadas em Pereira (2014). Todavia, a forma como tais dados foram expressos nos permite perceber a importância da interação entre os estudantes e com o professor na discussão e o modo não linear e mais aberto por intermédio do qual o conhecimento científico escolar vai surgindo ao longo das conversas entre os estudantes.

No Quadro 3, aparecem dados relativos à retomada do conceito de equilíbrio térmico, a qual aconteceu de forma compartilhada dentro do grupo, com a participação da Aluna 16 e dos Alunos 1 e 3.

Quadro 3. Retomada do conceito de equilíbrio térmico pela memória científico-afetiva

\begin{tabular}{|l|l|l|l|}
\hline $\begin{array}{c}\text { Conhecimento físico relativo à } \\
\text { memória científico-afetiva }\end{array}$ & Turnos & Informantes & \multicolumn{1}{|c|}{ Dados (em itálico) } \\
\hline Conceito de equilíbrio térmico & {$[138]$} & Aluna 16 & $\begin{array}{l}\text { Escrever só equilíbrio térmico... Fica } \\
\text { esquisito... Equilíbrio térmico... }\end{array}$ \\
\cline { 2 - 5 } & {$[140]$} & Aluno 3 & $\begin{array}{l}\text { É quando... dois corpos de temperatura } \\
\text { diferente dentro de um... calorímetro }\end{array}$ \\
\cline { 2 - 5 } & {$[141]$} & Aluna 1 & Ai, eles vão pra mesma temperatura \\
\cline { 2 - 5 } & {$[142]$} & Aluno 3 & Isso \\
\hline
\end{tabular}

Fonte: elaborado pelas autoras. 
No Quadro 4, aparece a retomada de um conhecimento científico escolar bastante específico: a densidade da água entre $0{ }^{\circ} \mathrm{C}$ e $4{ }^{\circ} \mathrm{C}$, por conta de sua dilatação anômala nesse intervalo de temperatura. Tal conhecimento tinha sido abordado pelo professor no ano anterior por intermédio do exemplo do congelamento somente da superfície de um lago, o qual também foi retomado pelos estudantes, com a mediação da pesquisadora.

Quadro 4. Retomada da densidade da água no exemplo do congelamento da superfície do lago

\begin{tabular}{|c|c|c|c|}
\hline $\begin{array}{l}\text { Conhecimento físico relativo à } \\
\text { memória científico-afetiva }\end{array}$ & Turnos & Informantes & Dados (em itálico) \\
\hline \multirow{9}{*}{$\begin{array}{l}\text { Densidade (exemplo do } \\
\text { congelamento somente da } \\
\text { superfície de um lago) }\end{array}$} & [288] & Pesquisadora & $\begin{array}{l}{[\ldots] \text { Quando ela aumenta de tamanho, a }} \\
\text { tendência dela é subir ou é descer? }\end{array}$ \\
\hline & [289] & Aluna 16 & Quando ela aumenta? \\
\hline & [290] & Aluno 19 & Subir. \\
\hline & [291] & Aluna 16 & Subir. \\
\hline & [292] & Aluno 19 & Densidade menor. \\
\hline & [293] & Pesquisadora & Subir por quê? \\
\hline & [294] & $\begin{array}{l}\text { Aluna } 16 \text { e } \\
\text { Aluno } 19\end{array}$ & Densidade é menor \\
\hline & [295] & Pesquisadora & $\begin{array}{l}\text { Densidade menor. Por que a densidade } \\
\text { é menor? }\end{array}$ \\
\hline & [296] & Aluno 19 & Porque tá maior com a mesma massa \\
\hline
\end{tabular}

Fonte: elaborado pelas autoras.

Mais uma vez observamos uma retomada de conhecimento científico escolar, pela memória cientifico-afetiva, de forma compartilhada pelos integrantes do grupo, mas, agora, com a colocação de perguntas pela pesquisadora, a fim de orientar os alunos em direção a esse conhecimento.

Já no Quadro 5, a retomada da lei dos gases ideais aconteceu de forma parcial, com o auxílio do professor. As interações entre ele, o Aluno 16 e a Aluna 1 evidenciaram que ela retomou a relação matemática da lei dos gases ideais, o que entendemos que pode ser categorizado como pertencente à memória científico-afetiva. Entretanto, a Aluna 1 inicialmente não associou a relação matemática ao conhecimento físico relativo a ela, pedindo a ajuda do professor para isso. 
Quadro 5. Retomada da lei dos gases ideais pela memória científico-afetiva

\begin{tabular}{|c|c|c|c|}
\hline $\begin{array}{l}\text { Conhecimento físico relativo à } \\
\text { memória científico-afetiva }\end{array}$ & Turnos & Informantes & Dados (em itálico) \\
\hline \multirow[t]{7}{*}{ Lei dos gases ideais } & [28] & Aluna 1 & $\begin{array}{l}\text { Professor, como é que era o nome daquela } \\
\text { matéria... }\end{array}$ \\
\hline & [29] & Aluno 19 & $\begin{array}{l}\text { Pivitipovotó. [referindo-se à lei dos } \\
\text { gases ideais] }\end{array}$ \\
\hline & [30] & Aluna 1 & ... que tinba a fórmula PV igual a $n \mathrm{RT}$ ? \\
\hline & [31] & Professor & Gases \\
\hline & [32] & Aluna 1 & Isso aí. Vou anotar. \\
\hline & [33] & Professor & Gases ideais \\
\hline & [34] & Aluna 1 & Eu lembrei da fórmula... \\
\hline
\end{tabular}

Fonte: elaborado pelas autoras.

Mesmo que a memória cientifico-afetiva possa englobar conhecimentos incompletos ou superficiais, como no exemplo do Quadro 5, entendemos que sua relevância para a aprendizagem pode ser evidenciada por contraste, ou seja, imaginando-se que não fosse possível interpretar a sua existência com base nos dados. Nesse caso, os estudantes não teriam se lembrando de nada relativo ao que foi ensinado nas aulas do ano anterior e, consequentemente, não teriam sido capazes de retomar, em situações novas, o que foi estudado anteriormente. Tal resultado demandaria uma investigação sobre as possíveis causas dessa não retomada, a qual seria um possível indicativo de não aprendizagem por parte deles. Assim, usando o argumento inverso, a memória científico-afetiva é um primeiro construto geral a indicar uma possível elaboração de conhecimento científico escolar por parte dos estudantes.

Assumimos que a retomada pela memória cientifico-afetiva ao longo do tempo é um indício de aprendizagem. Contudo, o sujeito pode ter aprendido conhecimentos para os quais não forneceu dados empíricos de retomada pela memória científico-afetiva, ou porque não considerou tais conhecimentos relevantes para a realização da tarefa ou porque eles não lhe foram exigidos.

Defendemos a presença da dimensão da afetividade na memória que abrange aspectos científicos em concordância com nossa fundamentação teórica, pois, conforme já afirmado anteriormente neste texto, "[...] quem separou desde o início o pensamento do afeto fechou definitivamente para si mesmo o caminho para a explicação das causas do próprio pensamento [...]” (VIGOTSKI, 2009, p.16). Ademais, “[...] dentre as implicações da afetividade no desenvolvimento humano, os estudos apontam [...] a relação indissociável com a cognição e a capacidade de afetar de maneira positiva ou negativa, o processo de ensino e aprendizagem" (CACHEFFO; 
GARMS, 2011, p. 9). Entendemos que a dimensão afetiva dessa memória pode aparecer algumas vezes de forma explícita e muitas vezes de forma implícita, mas que, na perspectiva vigotskiana do sujeito, ela estará sempre presente. Tal dimensão se refere ao modo como os sujeitos foram afetados pelas interações sociais que caracterizaram as atividades de ensino e aprendizagem.

Mesmo na discussão em pequeno grupo, expressa nos Quadros 3, 4 e 5, que parece bastante direcionada ao conhecimento científico escolar, há evidências de relação explícita com os momentos iniciais de aprendizagem, como no caso do turno [28], da Aluna 1, no Quadro 4, no dado "Professor, como é que era o nome daquela matéria". Ademais, no Quadro 3, a retomada de um tema bastante pontual, no contexto do mesmo exemplo específico dado pelo professor na aula do ano anterior, pode ser um indício de que os alunos foram afetados positivamente por esse assunto em particular e/o pelo modo pelo qual o mesmo foi abordado pelo docente.

Tudo aquilo que o sujeito retoma dos momentos do ensino de Física e que não tem relação explícita com o conhecimento científico escolar foi incluído na categoria denominada memória afetivo-vivencial. Tal memória não se refere diretamente a nenhum conhecimento científico escolar, mas evidencia o modo como o sujeito foi afetado por um conhecimento, por uma interação com o outro ou por uma dada situação relativa a seu processo de aprendizagem.

No dado "Lembro do men seminário que me passou de periodo sobre Matrizes Energéticas Biomassa" (Grupo 4), entendemos que o grupo expressou uma relação afetiva positiva com o seminário apresentado, já que ele foi visto como algo que ajudou na aprovação dos alunos (pelo menos, na aprovação de quem escreveu o texto, pois o fez na $1^{\text {a }}$ pessoa do singular). Tal dado, relativo à parte escrita da Atividade 1: Sensibilização dos alunos para as situações de aprendizagem da disciplina Física II e para os assuntos nela trabalhados, mencionada no Quadro 1, foi categorizado como pertencendo à memória afetivo-vivencial.

$\mathrm{Na}$ mesma atividade, os alunos do Grupo 3 expressaram elementos afetivos ao escreverem 'Desespero; Medo; Passei!!! Uhulll!'. Entendemos que eles retomaram, pela memória afetivovivencial, os sentimentos e sensações vivenciados nas aulas de Física de 2012.

Assim, entendemos que situações vivenciadas e sentimentos relativos a elas que podem dar sentido às retomadas ou não pela memória científico-afetiva pertencem ao que denominamos memória afetivo-vivencial. Esta última se refere tanto a situações em que os indivíduos foram afetados positiva como negativamente durante seu processo de aprendizagem.

Consideramos que os alunos foram afetados positivamente quando as relações que estabeleceram com o professor, com os demais colegas, com as situações de aprendizagem, com o conhecimento científico escolar e com seus próprios sentimentos colaboraram para suas aprendizagens. Foram afetados negativamente quando os mesmos elementos não auxiliaram em seu processo educativo.

No Quadro 6, apresentamos alguns dos dados que foram categorizados como pertencentes ao âmbito da memória afetivo-vivencial. Eles são fragmentos de respostas escritas pelos estudantes a um questionário com perguntas abertas, relativo à Atividade 2: Reflexão sobre a aprendizagem durante a disciplina Física II. Em especial, tais dados são algumas das respostas dos alunos ao serem questionados sobre o que acreditavam que os influenciou a aprender. Uma descrição mais detalhada da Atividade 2 pode ser vista em Pereira (2015).

No Quadro 6 aparecem dados em que características da perspectiva de ensino do professor (as aulas dinâmicas, a forma de ensinar do professor, aprender com exemplos do dia-a-dia, as maravilhosas explicações) ou o professor diretamente (termos um excelente professor) são citados pelos alunos como 
tendo contribuído para a sua aprendizagem. Como tais retomadas se referem não diretamente a um conteúdo de Física ministrado, mas sim a formas de interação com o professor e com o conhecimento científico escolar que caracterizaram as situações de sala de aula vivenciadas pelos estudantes, entendemos que se referem ao âmbito do que denominamos memória afetivovivencial. Em especial, entendemos que tais retomadas evidenciam uma relação afetiva positiva estabelecida entre os estudantes e o professor e entre eles e a perspectiva de ensino do docente, pois eles atribuíram a esses elementos sua facilidade para aprender.

Quadro 6. Retomadas, pela memória afetivo-vivencial, do que os estudantes acreditavam que os influenciou a aprender

\begin{tabular}{|c|c|}
\hline Sujeitos & Dados (em itálico) \\
\hline Aluna 1 & $\begin{array}{l}\text { Oprofessor } \\
\text { As aulas dinâmicas } \\
\text { As práticas feitas em laboratório }\end{array}$ \\
\hline Aluna 2 & Primeiramente o professor, que soube ensinar muito bem materia \\
\hline Aluna 7 & A forma de ensinar do professor \\
\hline Aluna 9 & $\begin{array}{l}\text { Termos um excelente professor } \\
\text { Aprender com exemplos do dia-a-dia, como da panela de pressão ou do azulejo e sua dilatação }\end{array}$ \\
\hline Aluna 11 & Com certeza... o modo em que o professor deu a matéria \\
\hline Aluna 18 & As explicações bem feitas em sala de aula \\
\hline Aluna 22 & As maravilhosas explicações do professor \\
\hline
\end{tabular}

Fonte: elaborado pelas autoras.

Assim, o termo vivencial, utilizado na categoria memória afetivo-vivencial, refere-se à importância também do aspecto cognitivo das interações sociais na constituição dessa memória. Entendemos que o aspecto cognitivo da memória afetivo-vivencial se faz presente à medida que o sujeito que sente e é afetado pelas relações sociais só o faz porque conhece, aprende e desenvolve a cada dia formas de estar no mundo e de se relacionar com os demais e com as situações sociais que the permitem ser afetado por elas.

Um exemplo de desenvolvimento de formas de relacionamento com os demais, as quais envolvem aspectos afetivos, foi identificado no início da aplicação da Atividade 3: Contraste entre os conceitos espontâneos e cientificos de calor e temperatura. Nela, os alunos foram orientados a resolver, em grupos, uma questão de Física sobre os conceitos de calor e temperatura. 
Inicialmente, no grupo analisado, a Aluna 1, apoiada pela Aluna 16, questionou o professor sobre o fato de que os grupos formados deveriam ter os mesmos integrantes que os das atividades da disciplina Física II. A Aluna 1 utilizou como argumento um elemento afetivo, qual seja, o fato de ela e a Aluna 16 terem feito outras amizades ao longo do tempo.

\author{
[87] Aluna 1: Professor, não tem isso daí que não pode mudar de grupo... \\ [89] Aluna 1:... Por que que não poder mudar? \\ [91] Aluna 1: Por que en fir, olha só, Professor, deixa en contar... \\ [93] Aluna 1: Só que en fir novas amizades, como a Aluna 16 fez novas amizades.. \\ [93] Aluna 16: É. \\ [94] Aluna 1: Entendeu? Ela, por exemplo... \\ [95] Aluna 16: É para ficar o mesmo grupo do segundo periodo ou...? \\ [96] Professor: É o mesmo grupo daquela época. \\ [97] Aluna 1: Tudo bem, Professor...
}

Interpretamos que as Alunas 1 e 16 acreditam que as relações interpessoais podem influenciar aspectos cognitivos, ou seja, a realização da atividade proposta pelo professor, por isso, pediram para formar outros grupos. No entanto, o professor informou que os grupos deveriam ser mantidos.

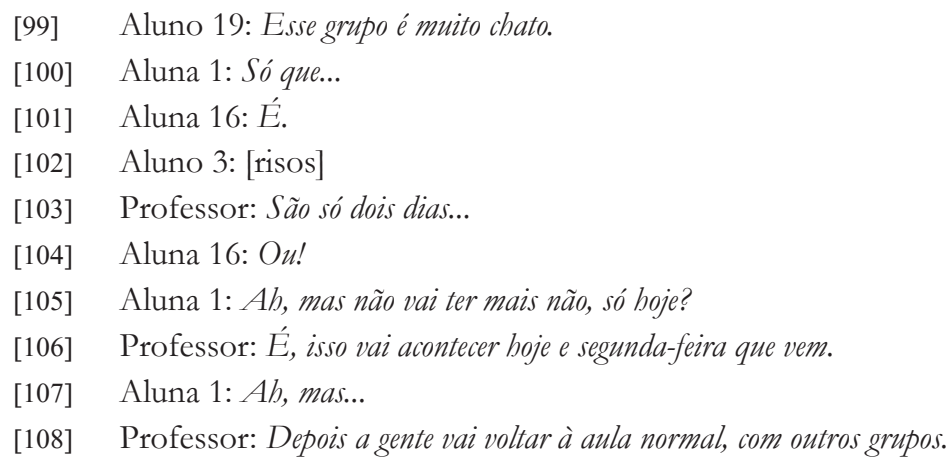

A partir deste momento, o tom de ironia invadiu o grupo. Os alunos começaram a brincar entre si sobre a questão da formação dos grupos e o ambiente descontraído que se formou contagiou também o professor.

[109] Aluno 19: [irônico] Aí eu não preciso mais falar com eles...

[110] Aluna 16: Ah, tá.

[111] [risos]

[112] Professor: [irônico] Aí você nunca mais precisa olhar para ele... [risos]

[113] Aluna 1: Pô, graças a Deus, Professor...

[114] Aluna 16: [dirigindo-se a Aluno 19] Abusado!

[115] Aluna 1: [irônico] Não aguento mais. Não aguento mais.

[116] Professor: É só porque...

[117] Aluna 16: Tá vendo, ela não me ama... Tô de mal, agora. 
Finalizando a conversa com os alunos do grupo, o professor argumentou que os grupos deveriam ser mantidos por conta da pesquisa realizada, que envolvia a retomada de conversas do ano anterior.

[118] Professor: ... Pra atividade da Pesquisadora... Tem que ter a mesma coisa do outro periodo.

[119] Aluna 1: Por quê?

[120] Aluna 16: [tom de aprovação] Porque é a Pesquisadora...

[121] Professor: Porque os registros vão estar aqui...

[122] Aluna 16: ... Eles estão em outro grupo.

[123] Professor: São as conversas que vocês mais ou menos estão retomando daquela época, então, tem que ser as mesmas pessoas, entendeu?

[124] Aluno 19: Ah... E tem como a gente ouvir as conversas de antes?

[133] Professor: Vamo lá, esse grupo tem que ser mantido, tá?

[134] Aluna 16: [tom de aprovação] Tá bom...

A partir do turno [136], os alunos voltaram a falar sobre o tema da atividade e não retomaram esse problema inicial sobre a constituição dos grupos. Mesmo diante de possíveis diferenças pessoais, de falta de afinidade ou da vontade de estarem em outros grupos, os estudantes não encontraram dificuldade no gerenciamento do trabalho coletivo, envolvendo-se intensamente na discussão, que teve 440 turnos de fala em 33min03s de gravações em áudio. $O$ episódio que aqui descrevemos ilustra que os aspectos afetivos, como defendido por nós neste trabalho, têm um importante papel no contexto educativo.

É relevante destacar também a pertinência das mediações do professor para resolver o impasse criado no grupo e o ambiente agradável e descontraído que ele ajudou a construir com suas intervenções, o qual pode ter contribuído para manter o grupo participativo ao longo de toda a discussão que se seguiu. Sua atuação no grupo está em consonância com o que afirmam Leite e Tassoni (2002, p. 136):

[...] as relações de mediação feitas pelo professor, durante as atividades pedagógicas, devem ser sempre permeadas por sentimentos de acolhimento, simpatia, respeito e apreciação, além de compreensão, aceitação e valorização do outro; tais sentimentos não só marcam a relação do aluno com o objeto do conhecimento, como também afetam a sua auto-imagem, favorecendo a autonomia e fortalecendo a confiança em suas capacidades e decisões.

Assim, o professor foi capaz minimizar os efeitos da relação afetiva inicialmente negativa que as Alunas 1 e 16 estabeleceram com a forma de interação proposta por ele, pois tal relação poderia influenciar diretamente a realização da atividade.

\section{Considerações finais}

Apresentamos neste trabalho elementos que nos permitiram compreender as retomadas de conhecimentos e de situações vivenciadas pelos estudantes em aulas de Física de momentos 
anteriores de seu processo de escolarização. As categorias de análise elaboradas tiveram por objetivo sintetizar relações entre aspectos de nossa fundamentação teórica, os quais foram observados na análise dos dados construídos com base nos registros da pesquisa empírica realizada.

Em termos teóricos, as categorias memória científico-afetiva e memória afetivo-vivencialvisam associar a função psicológica superior relativa à memória, denominada por Vigotski (2007) como memória lógica, aos já indissociáveis aspectos afetivo e cognitivo humanos. Ao utilizar a perspectiva vigotskiana, para tentar compreender como ocorrem as retomadas ao longo do tempo, percebemos que elementos teóricos de nosso interesse apareciam de forma um pouco espaçada e não tão fortemente relacionados em sua obra. Por exemplo, sobre o papel da memória, de acordo com Bakhurst (2002, p. 240), “[...] em 1932 [Vygotsky] escreveu que, embora sua pesquisa tivesse sido bem sucedida em pôr em marcha o debate sobre memória, ela não produzira conclusões definitivas".

Assim, sentimos a necessidade de estabelecer relações teóricas entre memória, cognição e afetividade na perspectiva vigostkiana, a fim de ampliar e aprofundar nosso olhar sobre a aprendizagem de ciências. As categorias de memória apresentadas neste trabalho, que buscam sintetizar essas relações, foram elaboradas também em conexão dinâmica com os dados da pesquisa, os quais, em nosso entendimento, revelaram que as dimensões da memória, da cognição e da afetividade estão fortemente imbricadas na forma como os sujeitos realizam suas retomadas.

É importante ressaltar que essas categorias de memória são construtos teóricos que entendemos que auxiliam nossa análise; a memória em si, de fato, não é separada em blocos ou regiões dentro dos sujeitos, ou seja, os conhecimentos ou vivências dos estudantes não ocupam lugares próprios em uma ou outra memória, pois ambas estão fortemente associadas.

Alguns elementos que entendemos que se relacionam com a aprendizagem, mas que não são frequentemente mencionados nas pesquisas da área de ensino de ciências, como as retomadas que os estudantes fazem das situações de sala de aula e as relações afetivas que estabelecem (ou não) com o conhecimento, com a ciência, com o professor e com os colegas, foram evidenciados neste trabalho, considerando-os em sua relação dinâmica com o ensino e com o contexto sócio-histórico-cultural das situações de sala de aula e de seus atores.

A complexidade do processo de aprendizagem e de suas relações com o ensino frequentemente não nos permitirá afirmar que os alunos aprenderam ou não determinado assunto de Física. Ademais, muito provavelmente, pelas próprias características intrínsecas ao processo de aprendizagem, algo é aprendido com base nas múltiplas relações que o indivíduo, em sua relação com o outro, realiza em diferentes situações de contato com o conhecimento científico, o que nos impede de apontar um único fator como causa da aprendizagem.

No entanto, entendemos que as categorias de análise apresentadas neste trabalho podem auxiliar os pesquisadores e os próprios professores a ampliar suas percepções acerca dos processos de aprendizagem de Física, na medida em que as retomadas de conhecimento científico escolar pela memória científico-afetiva podem ser indícios de aprendizagem. Além disso, as retomadas pela memória afetivo-vivencial possibilitam a compreensão dos modos por intermédio dos quais o sujeito é afetado pelas relações que estabelece com o outro e com o conhecimento na sala de aula de Física, os quais influenciam fortemente sua aprendizagem ao longo do tempo. Assim, ainda que a memória afetivo-vivencial não revele diretamente indícios de aprendizagem nas suas mais variadas formas, ela constitui-se em um construto teórico que acreditamos que pode ser de interesse também dos professores, pois permite desvelar aspectos que podem orientá-los na elaboração de estratégias didáticas e de formas de intervenção junto aos alunos. 


\section{Referências}

ALMEIDA, S. H. V.; ANTUNES, M. M. A teoria vigotskiana sobre memória: possíveis implicações para a educação. In: REUNIÃO ANUAL DA ASSOCIAÇÃO NACIONAL DE PÓS-GRADUAÇÃO E PESQUISA EM EDUCAÇÃO, 28., 2005, Caxambu. Anais... Caxambu: ANPED, 2005. Disponível em: <http://28reuniao.anped.org.br/gt20.htm>. Acesso em: 6 set. 2016.

BARROS, S. S. Reflexões sobre 30 anos da pesquisa em ensino de física. In: VIANNA, D. M. et at. (Org.). Anais do VIII Encontro de Pesquisa em Ensino de Física. São Paulo: SBF, 2002. 1 CD-ROM.

BAKHURST, D. A memória social no pensamento soviético. In: DANIELS, H. (Org.). Uma introdução a Vygotsky. São Paulo: Loyola, 2002. p. 229-254.

CACHEFFO, V. A. F. F.; GARMS, G. M. Z. A afetividade nas produções do GT 20 (Psicologia da Educação) da ANPED. In: CONGRESSO NACIONAL DA PSICOLOGIA ESCOLAR E EDUCACIONAL, 10., 2011. Maringá. Anais... Maringá, 2011. Disponível em: <http://www.abrapee.psc.br/xconpe/trabalhos/1/16.pdf>. Acesso em: 6 set. 2016.

CARVALHO, A. M. P. Critérios estruturantes para o ensino das ciências. In: Org.). Ensino de ciências: unindo a pesquisa e a prática. São Paulo: Pioneira Thomson Learning, 2004. v. 1, p. 1-17.

CARVALHO, A. M. P.; GIL-PÉREZ, D. O saber e o saber fazer do professor. In: CASTRO, A. D.; CARVALHO, A. M. P. (Org.). Ensinar a ensinar: didática para a escola fundamental e média. São Paulo: Pioneira Thomson Learning, 2001. p. 107-124.

FINKEL, D. Dar clase con la boca cerrada. Valencia: Publications de la Universitat de Valencia, 2008.

IZQUIERDO, I. Memória. Porto Alegre: Artmed, 2002.

LEITE, S. A. S.; TASSONI, E. C. M. A afetividade em sala de aula: as condições de ensino e a mediação do professor. In: AZZI, R. G.; SADALLA, A. M. F. A. (Org.). Psicologia e formação docente: desafios e conversas. São Paulo: Casa do Psicólogo, 2002. p. 113-141.

MAHONEY, A. A.; ALMEIDA, L. R. Sentimentos e emoções: um estudo com professores do ensino superior. In: REUNIÃO ANUAL DA ANPED, 28., 2005, Caxambú. Anais... Caxambu: Anped, 2005. p. 1-7.

MARTÍNEZ, A. M.; TACCA, M. C. (Org.). A complexidade da aprendizagem: destaque ao ensino superior. Campinas: Alínea, 2010.

MERCER, N. The seeds of time: why classroom dialogue needs a temporal analysis. Journal of the Learning Sciences, Philadelphia, v. 17, n. 1, p. 33-59, 2008.

MOREIRA, H.; CALEFFE, L. G. Metodologia da pesquisa para o professor pesquisador. 2. ed. Rio de Janeiro: Lamparina, 2008. 
Memória, cognição e afetividade: ...

OLIVEIRA, M. K.; REGO, T. C. Vygotsky e as complexas relações entre cognição e afeto. In: ARANTES, V. A. (Org.). A afetividade na escola: alternativas teóricas e práticas. São Paulo: Summus, 2003. p. 13-34.

PEREIRA, M. M. Memória mediada na aprendizagem de física: problematizando a afirmação "Não me lembro de nada das aulas do ano passado!". 2014. Tese (Doutorado em Ensino de Física) - Ensino de Ciências (Física, Química e Biologia), Universidade de São Paulo, São Paulo, 2014.

. Sobre formas de avaliar a aprendizagem dos estudantes em atividades em grupo: algumas propostas aplicadas em aulas de física. In: SIMPÓSIO NACIONAL DE ENSINO DE FÍSICA, 21., 2015, Uberlândia. Anais... São Paulo: Sociedade Brasileira de Física, 2015. p. 1-6.

PEREIRA, M. M.; ANDRADE, V. A. Elaboração e resolução de questões pelos estudantes: um estudo de caso acerca de aspectos cognitivos e metacognitivos. Revista Ensino, Saúde e Ambiente, Niterói, v. 7, n. 1, p. 1-13, 2014. Disponível em: < http://ensinosaudeambiente. uff.br/index.php/ensinosaudeambiente/article/view/223/165>. Acesso em: 6 set. 2016.

PINO, A. A Afetividade e vida de relação. Campinas: UNICAMP, 2000. Mimeo.

SASTRE, G.; MORENO, M. O significado afetivo e cognitivo das ações. In: ARANTES, V. A. (Org.). A afetividade na escola: alternativas teóricas e práticas. São Paulo: Summus, 2003. p. 129-152.

TASSONI, E. C. M.; LEITE, S. A. S. Afetividade no processo de ensino-aprendizagem: as contribuições da teoria walloniana. Educação, Porto Alegre, v. 36, n. 2, p. 262-271, maio/ ago. 2013. Disponível em: <http://revistaseletronicas.pucrs.br/ojs/index.php/faced/article/ view/9584>. Acesso em: 6 set. 2016.

VASCONCELOS, C.; PRAIA, J. F.; ALMEIDA, L. S. Teorias de aprendizagem e o ensino/aprendizagem das ciências: da instrução à aprendizagem. Psicologia Escolar e Educacional, Campinas, v. 7, n. 1, p. 11-19, jun. 2003. Disponível em: <http:/ /dx.doi. org/10.1590/S1413-85572003000100002>. Acesso em: 6 set. 2016.

VIGOTSKI, L. S. A construção do pensamento e da linguagem. 2. ed. São Paulo: WMF Martins Fontes, 2009.

VIGOTSKI, L. S. A formação social da mente. 7. ed. São Paulo: WMF Martins Fontes, 2007.

Artigo recebido em 14/01/2016. Aceito em 24/02/2016.

Endereço para contato: Rua Cariús, 362, Campo Grande, CEP

23052-180, Rio de Janeiro, RJ, Brasil. 